\title{
DINÂMICA DA DORMÊNCIA EM GEMAS DE PESSEGUEIRO DAS VARIEDADES ELDORADO E ÁGATA
}

\section{Dynamic of dormancy in peach buds of 'Eldorado' and 'Ágata' varieties}

\author{
Paulo Roberto Campagnoli de Oliveira Filho* \\ Ruy Inácio Neiva de Carvalbo**
}

\section{Resumo}

O trabalho teve como objetivo a verificação da variação da intensidade de dormência nos períodos de abril a agosto, das variedades de pessegueiro Eldorado e Ágata cultivadas na Fazenda Gralha Azul, situada no município de Fazenda Rio Grande/PR. O experimento foi realizado com ramos de um ano de idade a cada 21 dias, avaliando-se a intensidade da dormência pelo método biológico de "estacas de nós isolados" em sala de crescimento com temperatura de $25^{\circ} \mathrm{C}$ e fotoperíodo de 16 horas em vasos com vermiculita umedecida como substrato. A avaliação foi realizada a cada 48 horas. A dormência foi mais intensa no começo do mês de maio para as duas variedades. Porém, a variedade Ágata apresentou, até o mês de junho, dormência mais intensa que a Eldorado. O tempo médio para aparecimento de folhas abertas (TMFA) foi semelhante de abril a agosto para a variedade Eldorado, porém para a variedade Ágata com o aumento da intensidade da dormência, ocorreu um maior TMFA. A taxa final de brotação (TF) de gemas vegetativas para o mês de abril foi semelhante e baixa para ambas as variedades, tendo-se elevado significativamente até o mês de agosto. Para a variedade Ágata nenhuma gema florífera brotou durante o experimento.

Palavras-chave: Prunus persicae, Gemas vegetativas, Gemas floríferas, Fisiologia.

\section{Abstract}

This work aimed to evaluate the dormancy intensity from april to august in peach buds of 'Eldorado' and 'Ágata' varieties in the orchard of Gralha Azul farm, located in Fazenda Rio Grande/PR, Brazil. One year old stems were collected in six dates from april to august to determine the intensity of dormancy based in the 'single node cuttings' biological test developed in conditions of long days (16 hours), temperature at $25^{\circ} \mathrm{C}$ and high humidity provided by the maintenance of the cuttings in vermiculite. Evaliations were realized in each 48 hours. The dormancy of two varieties was more intense in the begin of May. The bud dormancy of 'Ágata' were more intense than the 'Eldorado' buds. The medium time needed to open leaves (TMFA) was similar during the period to 'Eldorado' variety, but the TMFA of 'Ágata' variety increased with the increase of dormancy. The final budburst percentage was small and similar for both varieties and increased significantly during the period until August. There was no flower budburst of 'Ágata' buds during the studied period.

Keywords: Prunus persicae, Vegetative buds, Flower buds, Physiology.

\footnotetext{
Estudante de Agronomia, PUCPR, Campus São José dos Pinhais.

*" Eng. Agrônomo, Dr., Professor Adjunto I da PUCPR. Campus São José dos Pinhais, Rodovia BR 376, km 14, Cx. Postal 129, São José dos Pinhais - PR, CEP 83010-500 - E-mail: ruycarvalho@zipmail.com.br
} 


\section{Introdução}

Segundo Petri (1986), a dormência é a falta de capacidade de um órgão crescer quando as condições ambientais permitem o crescimento. Embora existam muitas definições para dormência, parece que nenhuma é completa, possivelmente devido à falta de conhecimento deste fenômeno complexo (CAMELATTO, 1990).

A dormência foi inicialmente classificada em três fases: a dominância apical, a dormência de inverno, e a dormência causada por um fator ambiental adverso que impede o desenvolvimento da gema. Estas fases foram resumidas, respectivamente, em uma nova terminologia: a paradormência, a endodormência e a ecodormência (LANG et al., 1985; LANG et al., 1987).

A determinação da natureza dos fatores internos e externos a uma gema que influenciam a dormência e de que forma os mesmos estão envolvidos na eco, para e endodormência, auxiliará os estudos de técnicas culturais que possibilitem o desenvolvimento de plantas de pessegueiro.

Os estudos iniciais envolveram principalmente a influência do clima ou outro fator exógeno à gema na dinâmica da dormência, porém raramente os fatores endógenos eram estudados como a fisiologia, o metabolismo e a morfogênese das gemas ao longo de um período de crescimento. Atualmente, admite-se que o crescimento ou não de uma gema é uma resposta à combinação de uma série de processos, não apenas ambientais ou inerentes à planta, mas também intra ou extrameristemáticos. Dentre estes processos, citam-se a organogênese, a elongação dos internódios e a expansão foliar, além da forte interação existente entre eles (CRABBÉ; BARNOLA, 1996).

O principal fator externo envolvido na dinâmica da dormência é a temperatura. É conhecida a influência das baixas temperaturas na quebra da dormência de gemas e a sua importância na fase da ecodormência (LAVARENNE et al., 1975; MAUGET, 1983; MAUGET; RAGEAU, 1988). Para que a planta supere este estado dormente e retome seu crescimento vegetativo, é necessário um clima com outono e inverno com temperaturas baixas. Porém, na região de Curitiba-PR, não são freqüentes temperaturas suficientemente baixas nesta época, necessitando-se recorrer ao uso de reguladores químicos para promover o desaparecimento da dormência. Se não ocorre um número suficiente de horas com baixas temperaturas e não são usados reguladores químicos, há um atraso na brotação, sendo que as gemas apicais brotam antes e inibem as gemas laterais, comprometendo a formação da estrutura da planta e afetando a capacidade produtiva da árvore (CHAMPAGNAT, 1989).

As variedades Ágata e Eldorado em estudo não necessitam de muitas horas de frio para haver a quebra de dormência. A Ágata necessita de aproximadamente 500 horas de temperatura inferior a $7,2^{\circ} \mathrm{C}$ durante o ano, e o destino da produção é a industrialização. Já a Eldorado é menos exigente em frio e tem dupla finalidade, para a indústria e o consumo in natura (RASEIRA; NAKASU, 1998).

Os fatores internos que influenciam a dormência dizem respeito a uma correlação ou interação entre diversos órgãos ou tecidos da planta. Durante uma fase de crescimento intenso a inibição de uma gema lateral é causada por uma fonte distante e é chamada de dominância apical. Graças à elevada produção de auxinas, os meristemas terminais desviam o suplemento de nutrientes a seu favor, competindo com os outros meristemas. Uma decapitação do ramo promove o crescimento dos meristemas laterais. Numa fase mais tardia de crescimento (outono), a fonte de inibição é mais próxima e é chamada de inibição foliar. Os meristemas terminais já pararam de crescer e a competição por água e nutrientes acontece com as folhas. Uma desfolha permite a brotação de algumas gemas laterais. Mais tarde, nem uma decapitação ou desfolha permite o crescimento das gemas laterais. Nesta fase, a fonte de inibição de brotação está no próprio ramo ou muito próxima ao meristema (CRABBÉ; BARNOLA, 1996).

Embora exista o método bioquímico (teste de nucleotídeos) para caracterizar o nível de dormência, o teste biológico de "estacas de nós isolados", desenvolvido na Universidade de Clermont-Ferrand na França, é o único que quantifica a profundidade de dormência, é prático e tem boa correlação com os testes bioquímicos (CRABBÉ; BARNOLA, 1996). Este método vem sendo utilizado com bastante freqüência em frutíferas temperadas, tais como pessegueiros (BONHOMME et al., 1999). Este é baseado no princípio da inibição correlativa, em que uma gema tem ação sobre a outra. Entretanto, quando se utilizam estacas contendo uma única gema, formadas a partir de hastes, este efeito é eliminado e a gema pode desenvolver todo seu potencial (CHAMPAGNAT, 1983).

O trabalho objetivou verificar a variação da intensidade da dormência durante o outono e inverno nas variedades de pessegueiro Eldorado e Ágata cultivadas na Fazenda Gralha Azul, situada em Fazenda Rio Grande/PR. 


\section{Materiais e Métodos}

Os ramos de pessegueiro foram coletados de plantas matrizes das variedades Eldorado e Ágata selecionadas no pomar de dois anos de idade na Fazenda Experimental Gralha Azul, que se localiza no Município de Fazenda Rio Grande/PR, pertencente à PUCPR, e levados ao Laboratório de Micropropagação de Plantas do Setor de Ciências Agrárias da UFPR.

A dormência foi avaliada por meio do teste biológico de "estacas de nós isolados". Este teste baseou-se na manutenção de estacas de ramos de um ano com cerca de $7 \mathrm{~cm}$ de comprimento mantendo-se nas mesmas apenas a gema superior e eliminando-se as outras. As estacas foram mantidas por 42 dias em condições controladas numa sala de crescimento a temperatura de $25^{\circ} \mathrm{C}$ e fotoperíodo de 16 horas em vasos com vermiculita umedecida como substrato. As avaliações foram realizadas a cada 48 horas. As variáveis analisadas foram baseadas nos seguintes parâmetros:

- Ponta verde (PV): aparecimento de modificações na coloração da gema, ficando esta com o ápice esverdeado.

- Gema verde (GV): aparecimento de modificações na coloração e forma da gema ficando esta com o ápice verde e inchado.

- Gema alongada (GA): constatação do alongamento das folhas sem estarem abertas.

- Gema aberta (Gab): aparecimento de folhas abertas.

Com base nestes parâmetros as seguintes variáveis foram calculadas:

- Tempo médio para brotação (TMB): número de dias passados entre a instalação do experimento em cada data e detecção do estágio PV.

- Taxa final de brotação (TF): porcentagem de estacas com gemas abertas.

- Tempo médio para aparecimento de folhas abertas (TMFA): número de dias passados entre o estágio PV e GAb.

O delineamento experimental foi o completamente casualizado num esquema fatorial (6x2) com quatro repetições e 10 estacas por parcela. Os fatores estudados foram as variedades (Eldorado e Ágata) e as datas de coleta (18/04; 09/05; 30/ 05; 20/06; 11/07 e 01/08).
Os dados obtidos foram analisados estatisticamente pelo programa SANEST e a comparação entre as médias de tratamentos foi feita pelo teste de Tukey ao nível de significância de 5\%.

As temperaturas locais foram monitoradas e realizou-se a somatória de horas de frio ocorridas até cada data de coleta (Tabela 1).

TABELA 1 - Número de horas de frio (HF), abaixo ou igual a $7,2^{\circ} \mathrm{C}$ ocorrida no período de abril a agosto de 2001, na região de Curitiba/PR, com base em dados fornecidos pelo SIMEPAR.

Table 1 - Number of hours of cold (HF), below or equal $7,2^{\circ} \mathrm{C}$ occurred in the period from April until August of 2001, in the region of Curitiba/PR, obtained from data supplied by SIMEPAR

\begin{tabular}{ccc}
\hline DATAS & $\mathrm{HF} \leq 7,2^{\circ} \mathrm{C}$ & $\mathrm{HF}$ acumuladas \\
\hline Até $18 / 04$ & 0 & 0 \\
$18 / 04-09 / 05$ & 15 & 15 \\
$09 / 05-30 / 05$ & 5 & 20 \\
$30 / 05-20 / 06$ & 11 & 31 \\
$20 / 06-11 / 07$ & 61 & 92 \\
$11 / 07-01 / 08$ & 48 & 140 \\
\hline TOTAL & 140 & \\
\hline
\end{tabular}

\section{Resultados}

O tempo médio para brotação (TMB) das variedades Eldorado e Ágata no mês de abril foi de 14,6 e 26,5 dias, respectivamente (Figura 1). O aumento do TMB verificado no começo do mês de maio caracterizou um pico na curva, indicando que neste período a dormência foi mais intensa, pois conforme Dreyer e Mauget (1986) a fase mais profunda da dormência é caracterizada por um pico do TMB. No mês de julho o TMB das duas variedades assemelharam-se em aproximadamente 15 dias. A queda do TMB no final do período estudado indicou a saída da dormência, demonstrando a capacidade de brotação natural das gemas a campo se houver um acúmulo de horas de frio suficiente para superar a dormência. Quando não ocorre um número suficiente de horas com baixas temperaturas e não forem aplicados reguladores químicos, há atraso na brotação e comprometimento na formação da estrutura da planta (CHAMPAGNAT, 1989). O maior período de frio foi entre junho e julho com 61 horas de frio abaixo de $7,2^{\circ} \mathrm{C}$, demonstrando que o menor TMB em agosto foi devido à diminuição da dormência ocasionada no período anterior (Tabela 1). 
FIGURA 1 - Tempo médio para brotação (TMB) das gemas vegetativas de pessegueiro das variedades 'Eldorado' e 'Ágata' no período de 18/04 a 01/08 de 2001. Médias seguidas por letras distintas para cada variedade diferem entre si pelo teste de Tukey ao nível de significância de 5\%

Figure 1 - Average time for sprouting (TMB) of vegetative shoot in peach trees for the varieties ' Eldorado ' and 'Agate 'in the period of 18/04 until $01 / 08$ of 2001. Averages followed for distinct letters for each variety differ between itself using the Tukey test at 5\% significance level.
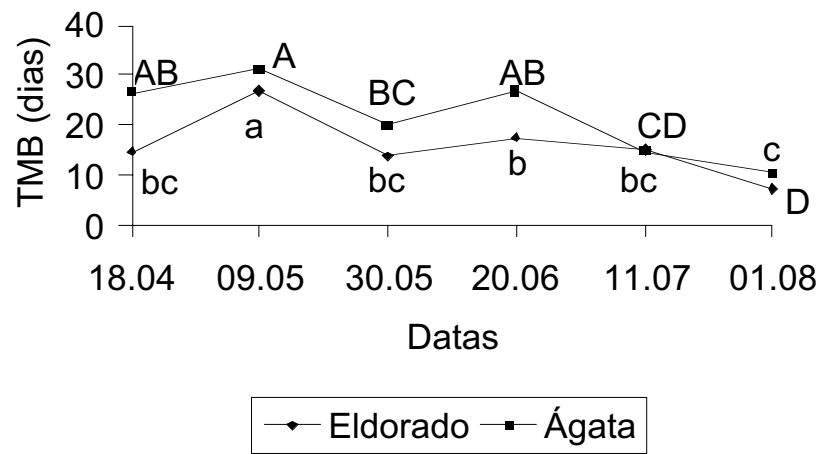

Não houve diferença significativa do tempo médio para aparecimento de folhas abertas (TMFA) para a variedade Eldorado (Tabela 2). Na variedade Ágata com o aumento da intensidade de dormência de abril para maio, houve também aumento do TMFA que foi reduzido significativamente apenas na última coleta em agosto, quando a dormência já havia sido liberada. A queda do TMB ao final do inverno normalmente está associ- ada à queda do TMFA demonstrando maior aptidão ao crescimento dos tecidos internos da gema, embora esta variação nem sempre ocorra de forma significativa (CARVALHO; ZANETTE, 1991; CARVALHO, 2001).

A taxa final de brotação (TF) das variedades Eldorado e Ágata foi semelhante e muito baixa (5\%) para o mês de abril (Tabela 2). A variedade Eldorado apresentou maior TF nos meses de junho (72,5\%) e agosto (80 \%) enquanto a variedade Ágata apresentou maior TF das gemas no mês de agosto (100\%). Apesar da TF ter se elevado para as gemas da variedade Eldorado ao longo do período estudado, não atingiu o valor máximo, mostrando que a sua dormência não foi totalmente e homogeneamente quebrada em todas as gemas.

Apenas para a variedade Eldorado ocorreu brotação de gemas floríferas, porém em pequena quantidade e localizada no final do período de dormência (Tabela 3). Para a variedade Ágata nenhuma gema florífera brotou. Supõe-se que a baixa quantidade de horas de frio abaixo de $7,2^{\circ} \mathrm{C}$ (140 horas) ocorrida no período foi uma importante causa desta ausência de brotação na variedade Ágata, pois o frio ocorrido não alcançou a sua exigência de aproximadamente 500 horas (RASEIRA; NAKASU, 1998). Já na variedade Eldorado, por ser menos exigente em frio, como afirma Raseira e Nakasu (1998), somente no final do período de dormência houve brotação, porém a heterogeneidade de brotação indica que as gemas floríferas podem ter sua dormência associada a outros fatores também importantes, além da temperatura, como o fotoperíodo.

TABELA 2 - Tempo médio para aparecimento de folhas abertas (TMFA) e taxa final de brotação (TF) de gemas vegetativas de pessegueiro das variedades 'Eldorado' e 'Ágata' no período de 18/04 a 01/08 de 2001.

Table 2 - Average time for open leaf appearance (TMFA) and final tax for the sprouting (TF) of vegetative shoot in peach trees for the varieties ' Eldorado ' and 'Agate 'in the period of 18/04 until 01/08 of 2001.

\begin{tabular}{|c|c|c|c|c|}
\hline \multirow[t]{2}{*}{ Datas } & \multicolumn{2}{|c|}{ TMFA (dias) } & \multicolumn{2}{|c|}{$\mathrm{TF}(\%)$} \\
\hline & Eldorado & Ágata & Eldorado & Ágata \\
\hline $18 / 04$ & $5,0^{\mathrm{ns}}$ & $3,0 \quad b^{*}$ & 5 & 5 \\
\hline $09 / 05$ & 5,1 & $4,4 \mathrm{ab}$ & $40 \mathrm{ab}$ & $80 \mathrm{ab}$ \\
\hline $30 / 05$ & 5,2 & 5,9 a & $25 \mathrm{bc}$ & $50 \quad b c$ \\
\hline $20 / 06$ & 5,4 & $4,0 \mathrm{ab}$ & 72,5 a & 35 \\
\hline $11 / 07$ & 2,9 & $3,9 \mathrm{ab}$ & $57,5 \mathrm{ab}$ & $80 \mathrm{ab}$ \\
\hline $01 / 08$ & 2,8 & $1,8 \quad \mathrm{~b}$ & $80 \mathrm{a}$ & $100 \mathrm{a}$ \\
\hline
\end{tabular}

* Médias seguidas por letras distintas nas colunas diferem entre si pelo teste de Tukey ao nível de significância de 5\%.

ns Diferença entre médias não significativa. 
TABELA 3 - Tempo médio para brotação (TMB), tempo médio para aparecimento de folhas abertas (TMFA) e taxa final de brotação (TF) de gemas floríferas de pessegueiro das variedades 'Eldorado' e 'Ágata' no período de $18 / 04$ a $01 / 08$ de 2001.

TABLE 3 - Average time for sprouting (TMB), average time for open leaf appearance (TMFA) and final tax for sprouting (TF) of flowering shoot in peach trees for peach trees of the varieties 'Eldorado 'and 'Agate' in the period of 18/04 until 01/08 of 2001.

\begin{tabular}{lcccccc}
\hline Datas & \multicolumn{3}{c}{ Eldorado } & \multicolumn{3}{c}{ Ágata } \\
\cline { 2 - 7 } & TMB & TMFA & TF & TMB & TMFA & TF \\
& $($ dias $)$ & $($ dias $)$ & $(\%)$ & $($ dias $)$ & $($ dias $)$ & $(\%)$ \\
\hline $18 / 04$ & $-*$ & - & 0 & - & - & 0 \\
$09 / 05$ & - & - & 0 & - & - & 0 \\
$30 / 05$ & - & - & 0 & - & - & 0 \\
$20 / 06$ & 19 & 4.5 & 10 & - & - & 0 \\
$11 / 07$ & - & - & 0 & - & - & 0 \\
$01 / 08$ & 5.6 & 7.0 & 13.3 & - & - & 0 \\
\hline
\end{tabular}

* (-) Gemas não brotadas durante os 42 dias de avaliação.

\section{Considerações Finais}

A dormência foi mais intensa no começo do mês de maio para as duas variedades. Porém, a variedade Ágata apresentou, até o mês de junho, dormência mais intensa que a Eldorado.

O tempo médio para aparecimento de folhas abertas (TMFA) foi semelhante de abril a agosto para a variedade Eldorado, porém para a variedade Ágata com o aumento da intensidade da dormência, ocorreu um maior TMFA.

A taxa final de brotação (TF) de gemas vegetativas para o mês de abril foi semelhante e baixa para ambas as variedades, tendo-se elevado significativamente até o mês de agosto.

Para a variedade Ágata nenhuma gema florífera brotou durante o experimento.

\section{Referências}

BONHOMME, M. et al. Influence of three contrasted climatic conditions on endodormant vegetative and floral peach buds: analyses of their intrinsic growth capacity and their potential sink strength compared with adjacent tissues. Scientia Horticulturae, Amsterdam, v. 80, p. 157-171, 1999.
CAMELATTO, O. Dormência em fruteiras de clima temperado. Hortisul, Pelotas, v. 1, n.3, p.12-17, out. 1990.

CARVALHO, R. I. N. Dinâmica da dormência e do conteúdo de carboidratos e proteínas em gemas vegetativas e ramos de um e dois anos de macieira com ou sem frio suplementar. 2001. $134 \mathrm{f}$. Tese (Doutorado em Agronomia, Produção Vegetal) - Universidade Federal do Paraná, Setor de Ciências Agrárias, Curitiba, 2001.

CARVALHO, R. I. N.; ZANETTE, F. Avaliação da intensidade da dormência em gemas de macieira (Malus domestica Borkh.) das cultivares Gala e Melrose. Revista Brasileira de Fruticultura, Cruz das Almas, v. 13, n. 3, p. 205-211, 1991.

CHAMPAGNAT, P. Bud dormancy, correlation between organs, and morphogenesis in woody plants. Fiziologiya Rastenii, Moxow, v. 30, n. 30, 1983.

CHAMPAGNAT, P. Rest and activity in vegetative buds os trees. Ann Sci. For. Champenoux, v. 46 Supl., p. 9-26, 1989. 
CRABBÉ, J.; BARNOLA, P. A New Conceptual Approach to Bud Dormancy in Woody Plants. In: LANG,G.A. (Ed.). Plant Dormancy: physiology, biochemistry and molecular biology. [S. L]: CAB international, USA, 1996. p. 83-113.

DREYER, E.; MAUGET, J. C. Variabilité du niveau de dormance des bourgeons vegetatifs suivant les types de rameau d'une couronne de noyer (Juglans regia L.): comparaison des cultivars Franquette et Pedro. Agronomie, v. 6, n. 5, p. 427-435, 1986.

LANG, G. A. et al. Dormancy: toward a reduced universal terminology. Hortscience, v. 20, p. 809812, 1985.

LANG,G. A. et al. Endo-, para and ecodormancy: physiological terminology and classification for dormancy research. Hortscience, v. 22, p. 371178, 1987.

LAVARENNE, S.; CHAMPAGNAT, P.; ARNOLA, P. Influence d'une même gamme de températures sur I'entrée et la sortie de dormence des bourgeons du frêne (Fraximus excelsior L.). Physiologie Végétale, v. 13, p. 215-224,1975.
MAUGET, J. C. Etude de la levée de dormance et du débourrement des bourgeons du noyer (Juglans regia L., cv. Franquette) soumis à des témperatures supérieures à $15^{\circ} \mathrm{C}$ au cours de leur période de repôs apparent. Agronomie, v .3, p. 745-750, 1983.

MAUGET, J. C.; RAGEAU, R. Bud dormancy and adaptation of apple tree to mild winter climates. Acta Horculturae, v. 232, p. 101-108, 1988.

PETRI, J. L. Dormência da macieira. In: EMPRESA CATARINENSE DE PESQUISA AGROPECUÁRIA. Manual da cultura da macieira. Florianópolis: EMPRESA CATARINENSE DE PESQUISA AGROPECUÁRIA, 1986. p. 163-201.

RASEIRA, M. C. B.; NAKASU, B. H. Cultivares: descrição e recomendação. In: MEDEIROS, C.A.B.; RASEIRA, M.C.B. (Ed.) A cultura do pessegueiro. Pelotas: Embrapa: CPACT, 1998. p. 29-99 